Article

\title{
Full-Waveform LiDAR Pixel Analysis for Low-Growing Vegetation Mapping of Coastal Foredunes in Western France
}

\author{
Patrick Launeau ${ }^{1, *(\mathbb{D})}$, Manuel Giraud ${ }^{1}$, Antoine Ba ${ }^{1}$, Saïd Moussaoui ${ }^{2}$, Marc Robin ${ }^{3}$, \\ Françoise Debaine ${ }^{3}$, Dimitri Lague ${ }^{4}$ (i) and Erwan Le Menn ${ }^{1}$ \\ 1 Laboratoire de Planétologie et Géodynamique de Nantes, UMR CNRS 6112, Université de Nantes, \\ 2 rue de la Houssinière, 44322 Nantes, France; manuel.giraud@univ-nantes.fr (M.G.); \\ ba.antoine.nd@gmail.com (A.B.); erwan.lemenn@univ-nantes.fr (E.L.M.) \\ 2 Laboratoire des Sciences du Numérique de Nantes, UMR CNRS 6004, Ecole Centrale de Nantes, \\ 1 rue de la Noë, 44321 Nantes, France; said.moussaoui@ls2n.fr \\ 3 LETG-Géolittomer, UMR CNRS 6554, Université de Nantes, Campus Tertre, 44312 Nantes, France; \\ marc.robin@univ-nantes.fr (M.R.); francoise.debaine@univ-nantes.fr (F.D.) \\ 4 Géosciences Rennes, UMR CNRS 6118, Université de Rennes 1, Campus de Beaulieu, 35042 Rennes, France; \\ dimitri.lague@univ-rennes1.fr \\ * Correspondence: patrick.launeau@univ-nantes.fr; Tel.: +33-2-51125266
}

Received: 20 March 2018; Accepted: 20 April 2018; Published: 25 April 2018

check for updates

\begin{abstract}
The monitoring of coastal sand dunes requires regular high-resolution aerial photography along hundreds of kilometers of coastal strips. Light detection and ranging (LiDAR) is now the most widely used method for detailed topographic and vegetation studies. The aim of this work is to show how the full-waveform shapes returned from single or multiple targets can carry information relating to low-vegetation cover and ground roughness of dunes. This work focuses on marram grass, widely involved in the development of mobile dunes. Low-growing plants often exhibit identical pigmentary composition and can only be distinguished by the height of their foliage, which modifies the shape of the LiDAR waveform around the main returns at the top of the foliage. We show that ray tracing of full LiDAR waveforms on the regular grid of pixels of hyperspectral images, acquired synchronously, can resolve the confusion between low-vegetation gradients and bare sand by analyzing the waveform damping induced by cumulating microdiffusion on foliage height, but also with glint effects on the surface roughness of compact materials. Analysis of successive shorelines of wet to dry sand, sand to pioneer couch grass, and couch grass to consolidating marram grass can thereby be conducted routinely.
\end{abstract}

Keywords: full-waveform LiDAR; hyperspectral; coastal foredune; low-vegetation cover; ray tracing

\section{Introduction}

The French coastal dunes are classified as a natural habitat by the European Community (Council directive 92/43/EEC of 21 May 1992). Alongside the ecological interest and ecosystem-based services [1], the coastal dunes play an important role in the protection of man-made inland activities and facilities through their sand reservoir capacities [2,3] in the current coastal evolution context [4].

The foredune studied (mobile dune) is the seaward component of a wide transgressive sand-dune system along the south of Noirmoutier island, on the west coast of France. The foredune is partially covered with marram grass (Ammophila arenaria), which is described as "foredune engineers" [5,6], has a height between 0.3 to $0.5 \mathrm{~m}$, and often obscures the underlying topography [7]. Such vegetation has 
a strong impact on the dune morphology and dynamics, because it influences sediment transport by trapping dune sand [8].

Airborne remote sensing provides synoptic coverage of hundreds of kilometers of coastal dune strips at high spatial resolution and is well adapted to coastal dune inspection and monitoring. Light detection and ranging (LiDAR) is an active remote-sensing technique measuring the return time of a laser pulse backscattered by a target as an echo signal whose intensity is proportional to the reflectance properties of the target [9]. Classical LiDAR survey records discrete echoes in real-time but may not be able to distinguish targets that are too close to each other. The minimum target separation is typically $0.4 \mathrm{~m}$ in airborne LiDAR. However, recording the full waveform (FWF) of the backscattered signal and subsequent re-analysis of the signal offers the possibility of unmixing the echoes that have merged or of detecting new weak echoes that may have been missed during real-time in-flight detection [10]. Discrete echo classification of aboveground vegetation of coastal dune cover is usually classified as low (0-0.3 m), medium (0.3-2 m), and high ( $>2 \mathrm{~m}$ ) [11] (Doyle, 2017).

This work focuses on using the FWF record to detect very low aboveground vegetation of 0.2-0.5-m-tall marram grass and of 0.2-0.3-m-tall couch grass. Instead of mapping the vegetation with FWF Gaussian decomposition [12] retrieving echoes, we propose an alternative method by transforming digitized FWF into 400 band FWF ray tracing pixels (FWFp) in images to be processed without echo segmentation. With $0.15 \mathrm{~m}$ (or $1 \mathrm{~ns}$ ) resolution, each FWF pixel covers a vertical range of $60 \mathrm{~m}$ of LiDAR interaction with the ground and volumetric vegetation, the shape of which can be analyzed without any a priori knowledge. In addition, the proposed registration method offers the perspective of a joint analysis with hyperspectral images.

\section{Materials and Methods}

\subsection{Study Area and Data Acquisition}

The study area is a dune system located on the island of Noirmoutier (Figure 1a). The Tresson dune (Figure 1b) presents a wide landward transgressive dune system with a narrower seaward foredune. Typical vegetation habitats of these French Atlantic coastal dunes are as follows: (1) the foredune (mobile dune) with a narrow strip of low couch grass, Elymus farctus, on the incipient component of the foredune (Figure 1(b1)) followed by a larger strip of 0.2-0.5 $\mathrm{m}$ thick dense marram grass, Ammophila arenaria, on the established foredune with numerous sand blowouts generated by aeolian processes (Figure 1(b2)); (2) the fixed transgressive dune (grey dune) characterized by mosses (e.g., Tortula ruraliformis (brown moss) and Hypnum lutescens (green moss)) and other low plants; and (3) the back of the dune, which has different bushes and trees.

The Teledyne Optech Titan dual wavelength LiDAR (green $532 \mathrm{~nm}$, infrared $1064 \mathrm{~nm}$ ), managed by the Nantes Rennes university platform can record a FWF on one selected channel. It was installed to record the infrared signal, best suited to topographic and vegetation analysis as it has a bright reflector in the infrared. Its coupling, with a push broom hyperspectral HySpex camera for complementary study of the vegetation, is not presented in this work. The airborne campaign was conducted at an altitude of $1100 \mathrm{~m}$ with the cooperation of GEOFIT and PIXAIR companies on 7 September 2015 between 1:14 p.m. and 1:55 p.m. The scan angle of the rotating mirror was $\pm 11^{\circ}$ giving a field of view (FOV) of $22^{\circ}$ and a swath of $427.6 \mathrm{~m}$ on the ground with a nominal footprint of $0.41 \mathrm{~m}$ cross track. With an aircraft speed of $240 \mathrm{~km} / \mathrm{h}$ the down-track footprint varied from $0.47 \mathrm{~m}$ at nadir to $0.94 \mathrm{~m}$ sideways, defining a minimum size of resolution and ensuring complete coverage of the ground without a pixel gap. With a laser pulse frequency set to $200 \mathrm{kHz}$, the overall mean point density was 7.09 points $/ \mathrm{m}^{2}$ per wavelength. The FWFs were recorded with a maximum length of $54 \mathrm{~m}$ at $1 \mathrm{gHz}$ frequency, resulting in a vertical resolution of $0.15 \mathrm{~m}$. The Optech LiDAR Mapping Suite (LMS) combined with the global positioning system (GPS) and the inertial measurement unit (IMU) associated with the LiDAR to provide a georeferenced point cloud and associated FWF. The accuracy provided by GEOFIT Company 
was better than $0.15 \mathrm{~m}$ in planimetry and $0.08 \mathrm{~m}$ in height. A 1-m digital surface model (DSM) of the first returns envelope was generated for a quick overview (Figure 1c).

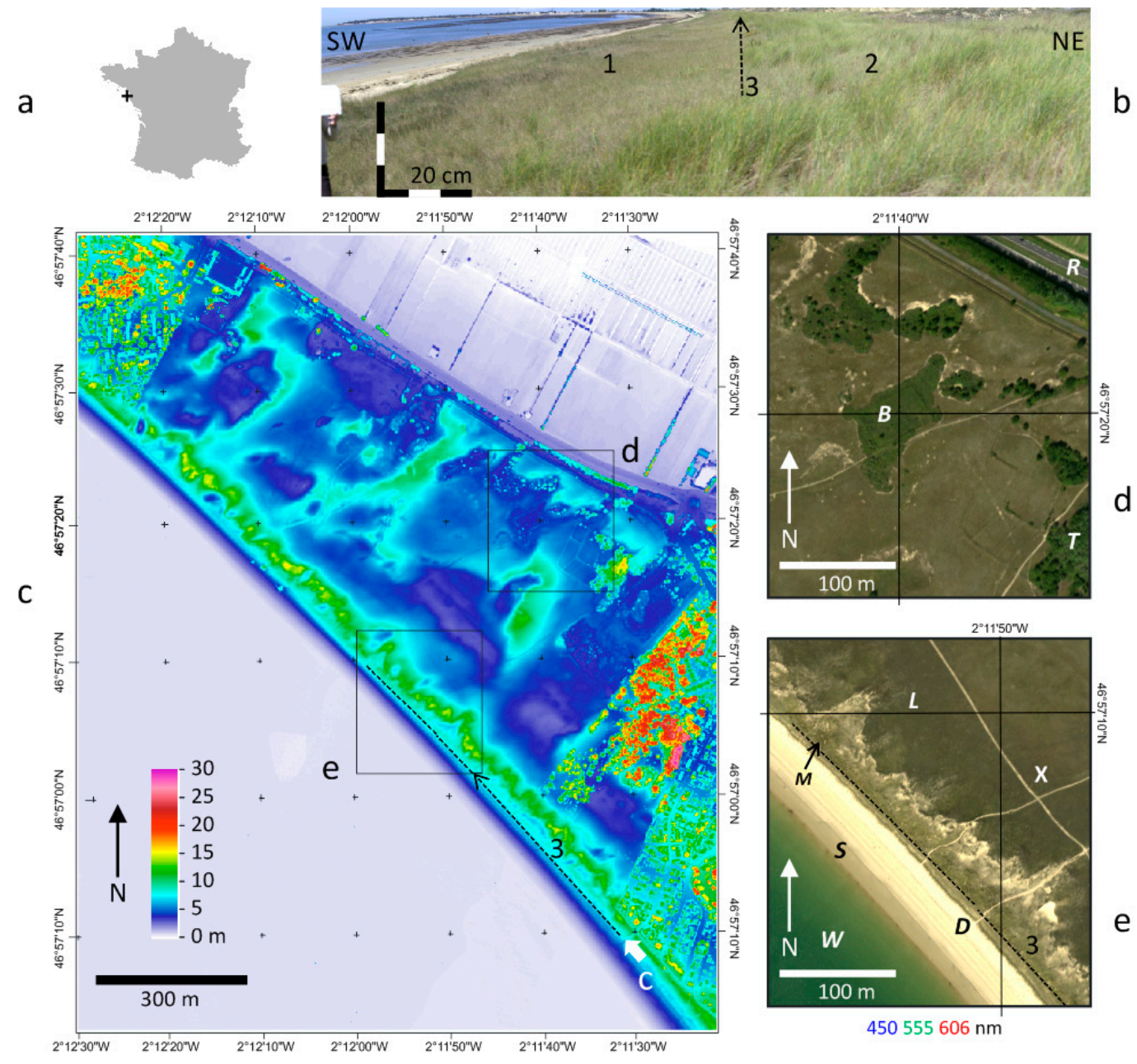

Figure 1. Localization of the study areas: (a) Noirmoutier island, western France; (b) ground panorama taken in 2017 on the axis (3) of the boundary between the couch grass on the left (1) and marram grass on the right (2); (c) digital surface model of the Tresson dune bordered by woods and partly urbanized in the northwestern and southeastern ends, cultivated polders on the northeastern side, and the Atlantic ocean at low tide on the southwestern side and the location of $(\mathbf{b}, \mathbf{d}, \mathbf{e})$; (d) first area of interest (AOI 1) showing bush (B), trees (T), and an asphalt road (R); and (e) second main area of interest (AOI 2) showing sea water (W), bottom wet sand (S), top dry beach sand (D), mobile dune marram grass $(\mathrm{M})$, fixed dune land $(\mathrm{L})$, and a sandy footpath $(\mathrm{X})$.

Given the flight altitude of $1100 \mathrm{~m}$, the hyperspectral camera FOV was extended to $34^{\circ}$ to produce a default spatial resolution of $0.4 \mathrm{~m}$ across-track and $0.8 \mathrm{~m}$ along-track, as close as possible to the LiDAR resolution. The resulting images were georeferenced using the LiDAR trajectory with Parametric Geocoding \& Orthorectification for Airborne Optical Scanner Data (PARGE) [13]. They will be presented in detail in a forthcoming publication but were useful to present here for their synchronous color output of the ground (Figure $1 \mathrm{~d}, \mathrm{e}$ ) and the reflectance image and spectra corresponding to various LiDAR data in order to better understand the results. The raw image was converted into radiance with factory calibration. The Atmospheric and Topographic Correction (ATCOR 4) model [13] was used to accurately convert radiance into relative reflectance by doublechecking on the dry sand ground control points. 


\subsection{Methodology}

\subsubsection{Full-Waveform Data Registration and Ray Tracing}

In order to combine the hyperspectral cube of regularly spaced pixels, whose third dimension is a wavelength of reflectance, it was necessary to convert the FWF data of the regularly spaced pixels on the ground and introduce a third dimension corresponding to the altitude of the reflection in voxels (FWFv), thus redistributing the FWF data on a spatial three-dimensional (3D) grid [14], as shown in Figure 2a. To preserve the same angle of view as a pixel in the hyperspectral image, we used a ray tracing procedure, which collected all the FWFs projected in each pixel, as seen in Figure $2 b$, without moving any value between the pixels. Unlike the FWF voxel, which straighten their geometry by registering each FWF record to the voxel of the closest vertical column (Figure 2c), the FWF ray tracing pixels (FWFp), like hyperspectral data, have $\mathrm{N}$ dimensions given by the number of FWF records and keep their scan angle orientation without moving any records between pixels (Figure 2d). Similar to [15-19] for voxelization but for data collection by ray tracing, we also used the mean FWF per pixel, which is the easiest way to link to the hyperspectral pixel, giving only one mean spectrum per pixel.
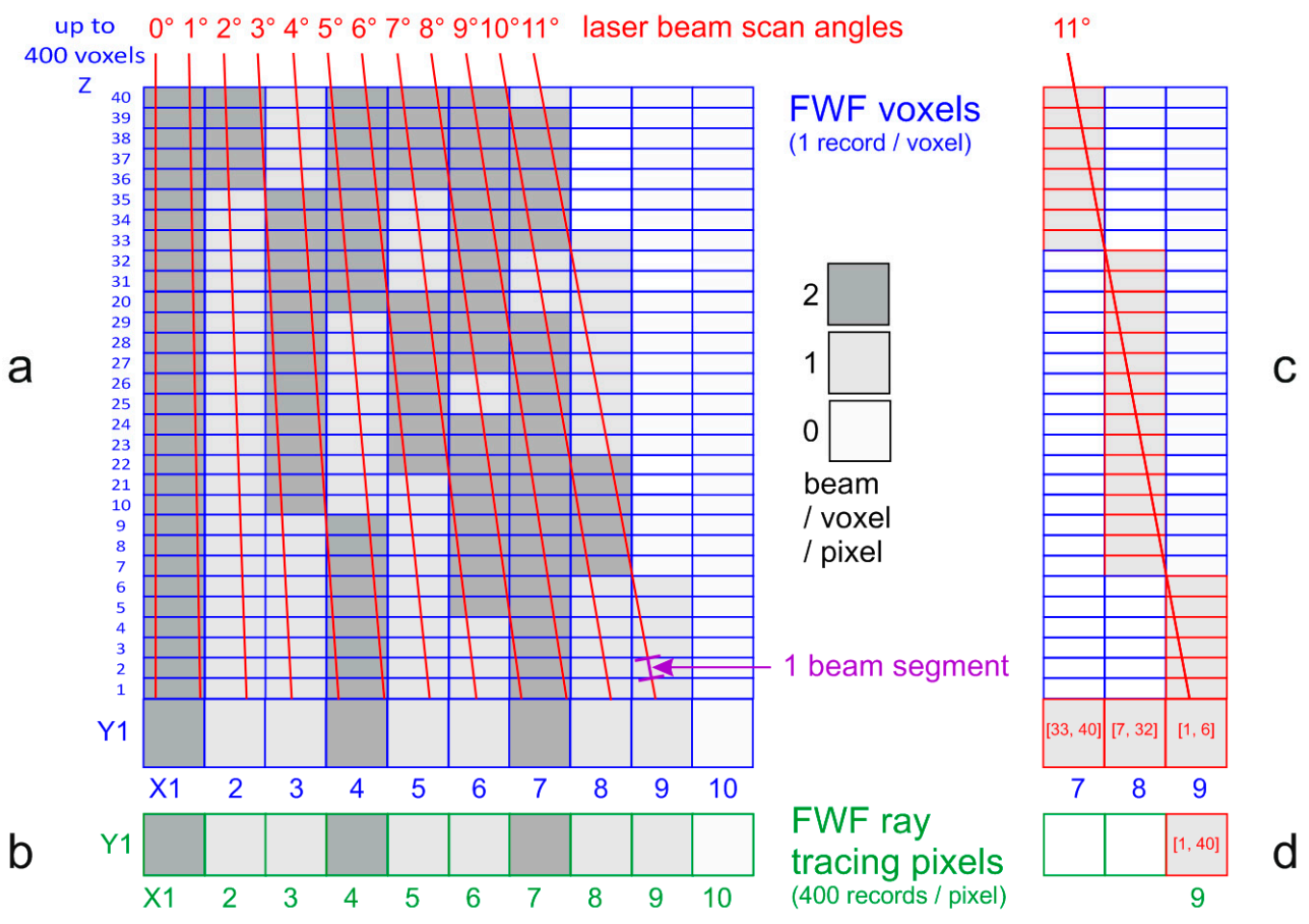

Figure 2. Full waveform (FWF) averaging along a line Y: (a) diagram of the voxelization example of 10 laser beams intersecting the $Y$ line section of an XYZ grid of voxels 0,1 , or 2 times; (b) strip X of one line $\mathrm{Y}$ used to localize ray tracing anchorage on pixels where FWF records are cumulated in a stack of $\mathrm{N}$ channels as in hyperspectral images, which therefore have the same light path; (c) the voxelization distributes the records of the $11^{\circ}$ scan angle in three successive columns of voxels $(7,8,9)$, whereas in (d), the ray tracing stacks all the records of the $11^{\circ}$ scan angle in the $\mathrm{N}$ channels of one single pixel (9). The resolution is $0.5 \mathrm{~m}$ in the $\mathrm{X}$ and $\mathrm{Y}$ directions and $0.15 \mathrm{~m}$ in the $\mathrm{Z}$ and $\mathrm{N}$ directions, with $\mathrm{Z}$ being perpendicular to $(\mathrm{X}, \mathrm{Y})$, whereas $\mathrm{N}$ is a number of channels along each laser beam scan angle.

In a full-waveform LAS (LASer) file format version 1.3, each discrete point is associated with a three-dimensional vector and a table of full-waveform points. The vector gives the direction of the reflected laser pulse. An elevation grid ranging from a minimal to a maximal elevation was used. The resolution of this grid is given by the temporal spacing of waveform points retrieved from the LAS file. For each discrete point, we used the associated three-dimensional vector to compute a 
simple line-plane intersection with a plane at the geoid elevation of our region of interest. Then, at the projected point, we accumulated the contribution of the associated waveform at each elevation into the chosen elevation grid. Finally, we average the contribution at each elevation on each projected laser pulse. So, each resulting full-waveform ray tracing pixel (FWFp) is a sort of "hyperspectral" pixel, where wavelengths have been substituted by LiDAR return intensities recorded in successive narrow bands of height along a range of absolute altitudes.

\subsubsection{Full-Waveform Pixel Normalization}

The comparison between FWFp shapes requires different normalizations in altitude and intensity. Instead of calibrating the waveform amplitude as in [12] for the absolute comparison between FWFp, we defined a relative intensity independent of the amplitude to measure only the scattering of the FWFp without any a priori knowledge of its shape. Then, a FWFp can be made of an infinite number of functions distributing relative intensities anywhere in the range of the FWFp.

One of the emitted pulses is presented in Figure $3 \mathrm{a}$ and is provided without a scale factor but with a characteristic shape capable of being retrieved on each return. The dry sand at the top of a beach, being similar in shape to the laser pulse emitted by the LiDAR and the main background of the study area, is used as a reference of neutral return ( $D$ in Figure 1e). Wet sand at the bottom of the beach ( $S$ in Figure 1e), $4 \mathrm{~m}$ below the altitude of the reference, is used as a first comparison in order to illustrate the proposed methodology. The Gaussian function fit on each FWF shows that each of them presents a short upward and long downward enlargement of their base as a function of damping, similar to the emitted pulse, which would be missed by working only using Gaussian fits. All three FWFp, emitted or backscattered, present various amplitudes at different heights or ranges (Figure 3a); a comparison of their shapes necessitates step by step normalizations.

The first step of the normalization is to remove the altitude effect by centering the FWFp on their maximum intensities, which usually correspond to their first main echo, shifting all of them on a common altitude 0 (Figure 3b). The darker wet sand centered FWFp (CFWFp) occupies a smaller area than the dry sand CFWFp because of a lower reflectance (Figure 3c). The wet sand being well-drained, there is not enough water on its surface to form an absorption feature at $940 \mathrm{~nm}$, unlike a wet sand pixel covered by a few-centimeters-thick layer of water (Figure 3c). The relative darkness of the sand is therefore not only due to its water content, but a large part of it comes from a water film optically connecting all the grains. This optical continuity allows the light to travel deeply into the sand, resulting in a lot less reflection between the aggregated grains. On the other hand, dry sand grains are not aggregated and better reflect the light. The reflection of the light is also proportional to the bidirectional reflection diffusion function (BRDF) [20] of the upper surface of the sand, which is strongly affected by the presence of surface ripples [21]. The roughness of a surface can therefore backscatter the light as a bright backward glint to the LiDAR detector or as a dark component depending on the incidence angle on the ripples. This BRDF effect is used by [22] as a radiometric calibration of the FWF. However, this technique relies on the hypothesis that FWF are Gaussian [23], which is not exactly the shape (Figure 3a) of the LiDAR emitted signal [24]. A Gaussian model would therefore lose the characteristic FWF damping inherited from the LiDAR emission (Figure 3b). Many other waveform fittings are available [10], mainly for peak detection and FWFp segmentation, in echoes that are not suitable for the hypothesis of FWFp of infinite numbers of tiny waveform contributions potentially distorted by all sort of materials. Theoretically, intensity corrections by model-driven correction of [25] are also available with atmospheric parametrization and the assumption of Lambertian reflectors on the ground similar to hyperspectral atmospheric correction (see Section 2.1). Hyperspectral image data acquired simultaneously are stored in integers as reflectance times $10^{4}$ (Figure $3 \mathrm{c}$ ) and the sum of the FWFp recorded in the same pixel area, using the same data coding and display values comparable to the reflectance. FWF data are digitized in nanoseconds, corresponding to $0.15 \mathrm{~m}$ in height, so, the summation per pixel of their footprints simulates an integration time equivalent to one hyperspectral pixel, which is consistent with the total sum of backscattering within the waveform 
of [12]. Although [26] shown the perfect correspondence between sand hyperspectral reflectance and LiDAR intensities, with almost no incident effect below $20^{\circ}$, it is however hazardous to fit FWFp sum on the reflectance because of the difference between the sun elevation and the laser beam scan angles, as explained later. Therefore, we used the comparison between fully calibrated hyperspectral reflectance at $986 \mathrm{~nm}$ and FWFp sum at $1064 \mathrm{~nm}$ as an indicator of reflection behavior, in particular, for the detection of glint or specular reflections not linked to the composition of the surface, as opposed to the diffusive reflections, which entered one or more particles [27].



a
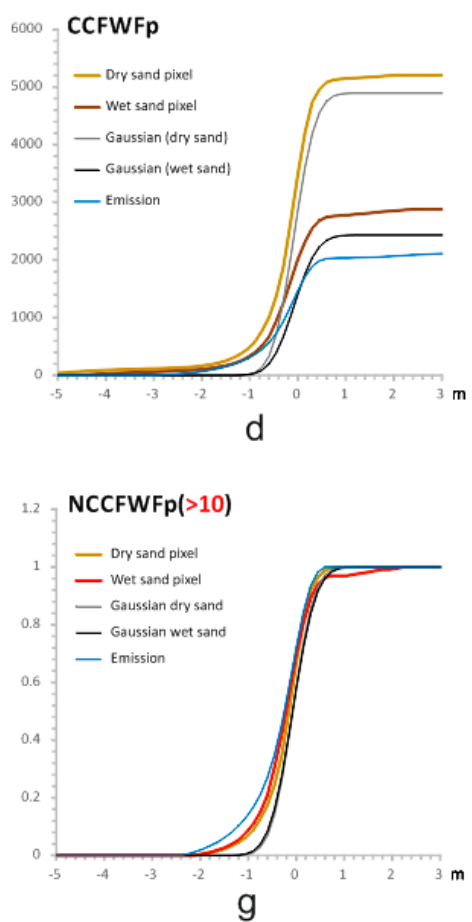

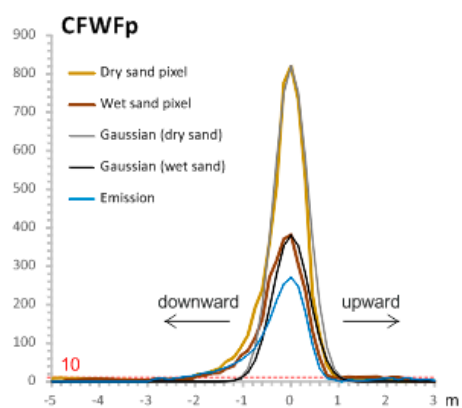

b
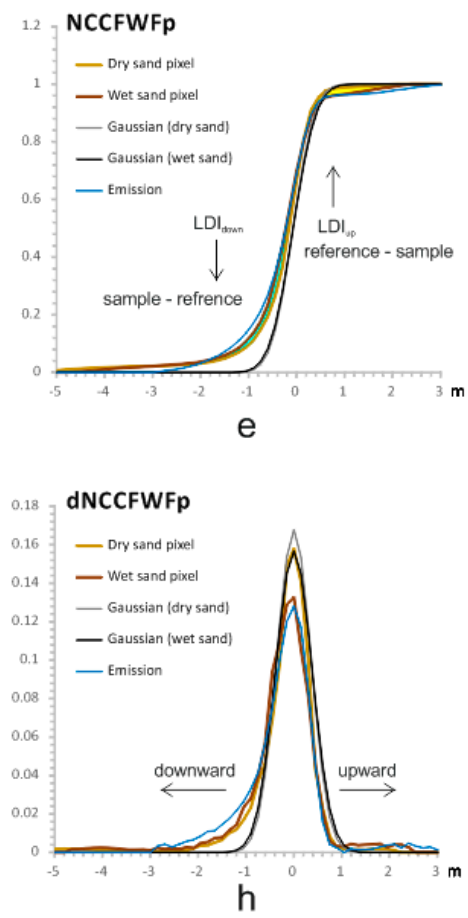

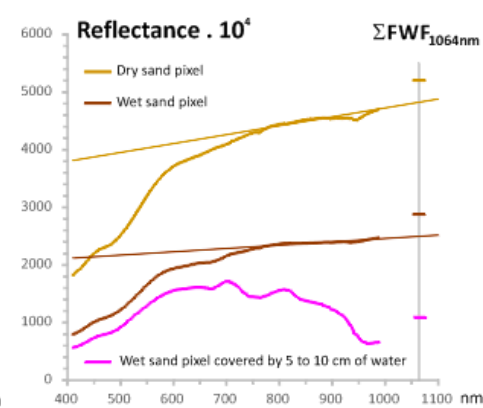

C
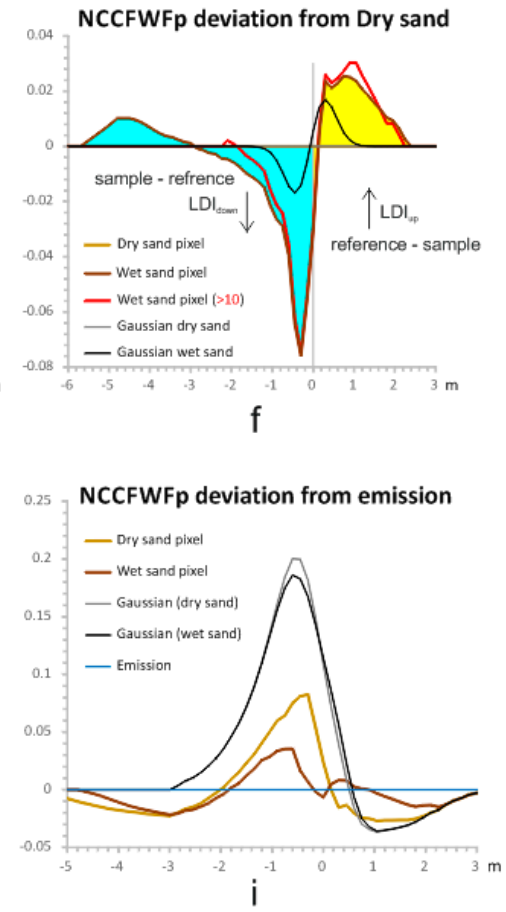

Figure 3. FWF analysis: (a) FWF ray tracing pixels (FWFp, DN) of dry and wet sand, their respective Gaussian fits, and shape (without a scale factor) of the emitted pulse; (b) centered FWFp (CFWFp); (c) corresponding reflectance in nanometers as stored in image files in integer times $10^{4}$ with a plot of FWFp sum at $1064 \mathrm{~nm}$, the magenta spectra and corresponding FWFp represent a pixel of wet sand covered by water chosen out of areas of sun glint; (d) cumulative centered FWFp (CCFWFp); (e) normalized cumulative centered FWFp (NCCFWFp); (f) NCCFWFp deviation from dry sand for (e,g); (g) normalized cumulative centered FWF greater than 10 (NCCFWFp > 10); (h) derivative of NCCFWFp of (e) (dNCCFWFp); and (i) NCCFWFp deviation from the emitted pulse for (e). FWF are given in relative units versus $\mathrm{m}$ with $0.149 \mathrm{~m}$ per channel. Reflectance samples are in reflectance times $10^{4}$ as stored in images. Upward and downward LiDAR diffusion indices (LDI) are discussed in the text. 
The second step of the normalization used cumulative centered FWFp (CCFWFp), which vary with reflectance intensity (Figure 3d). The normalization of all CCFWFp to their maximum values gives normalized CCFWFp (NCCFWFp) showing that both sands effectively return FWFp shapes quite similar to the emitted waveform, thus allowing the study to focus on FWFp damping whatever the reflectance intensity (Figure 3e). The FWFp damping level is potentially sensitive to noise levels, and a threshold of cumulative calculation set at 10 (Figure $3 \mathrm{~b}$ ) can produce an alternative NCCFWFp for FWFp greater than 10 (Figure 3g). All normalizations are applied at pixel size to minimize potential FWFp damping along slopes [28]. For instance, the mean FWFp of the dry sand reference taken on a beach slope displays a waveform enlargement due to the averaging of FWFp at different altitudes. This effect disappears by moving all FWFp to the same altitude by NCCFWFp calculation at pixel resolution prior to the calculation of a mean NCCFWFp dry sand reference. With a LiDAR footprint of $0.4 \mathrm{~m}$ collected in $1 \mathrm{~m}$ pixel, the centering of the waveform to the same altitude in each pixel minimized the slope effects on NCCFWFp, which was negligible for the vegetation diffusion effects as shown in the results.

The dry sand, being the least diffusive material of the study and with no specular effects, was used as a reference as in $[29,30]$. The deviation between dry and wet sand NCCFWFp (Figure 3f) enhances the detection of FWFp damping. The wet sand at the bottom of the beach is more compact. It presents a flat surface of grains sticking to each other with the help of a water film giving off light glint at the top of the sandflat, with backward or forward emergent angles, like tiny mirrors. The dry sand at the top of the beach is less compact and composed of loose grains facilitating the diffusion of the light more homogeneously in every direction, including detection by the LiDAR. This effect is well-evidenced by the difference between wet and dry sand (Figure 3f). On the contrary, because of the attendant glint effects on the long damping shape of the emitted laser beam itself, the wet sand displays a stronger and longer FWFp downward damping than the dry sand (Figure 3e). Considering this as noise, a threshold of 10 to shorten the NCCFWFp (Figure 3g) could be used. The resulting deviation of the wet to dry sand displays shorter downward function (Figure 3f). We did not use this threshold in the following application and found this deviation useful to detect the presence of flat compact surfaces exhibiting characteristic micro-specular reflections. The NCCFWFp deviation from the emitted waveform (Figure 3i) is stronger for the Gaussian fits, which tend to be similar to each other. The pattern of the upward diffusion was less characteristic (Figure 3i), and we used the dry sand reference, giving a more contrasted downward-upward pattern (Figure 3f) to study low-vegetation types on the sand dunes.

The NCCFWFp deviation from the dry sand (Figure 3f) presents positive values for upward diffusion and negative values for downward diffusion. A simple calculation of NCCFWFp deviation area in both positive and negative directions (arrows in Figure 3f) provides a convenient laser diffusion index (LDI), noted respectively as $\mathrm{LDI}_{\mathrm{up}}$ and $\mathrm{LDI}_{\text {down }}$, whose mean value is noted as $\mathrm{LDI}_{\text {mean }}$. $\mathrm{LDI}_{\mathrm{up}}$ is the sum of the reference NCCFWFp minus the sample NCCFWFp above the normalized height zero (yellow area Figure $3 \mathrm{e}, \mathrm{f}$ ), and LDI ${ }_{\text {down }}$ is the sum of sample NCCFWFp minus the reference NCCFWFp below the normalized height zero (blue area Figure 3e,f).

It is always possible to return to the original shape for clarity of the FWFp by the calculation of a derivative of the NCCFWFp (dNCCFWFp, Figure 3h). It is equal to the FWFp weighted by its area. The dNCCFWFp deviation from the dry sand (see Supplementary Material S1) is however, not used because it does not display large changes like the NCCFWFp (Figure 3f). In any case (from Figure 3a-i), the Gaussian fit never detects any asymmetrical changes like FWFp, which also justifies our decision to work on original FWFp shapes. The departure between FWFp and Gaussian fits is better exemplified by the cumulative curves (Figure 3e,g).

\section{Results}

FWFp samples corresponding to 50-300 pixels identified as the regions of interest (ROI) were collected in two areas of interest (AOIs, Figure 1e,d). The wavelength of the LiDAR laser beam at 
$1064 \mathrm{~nm}$ is compared to the last channel at $986 \mathrm{~nm}$ of the hyperspectral image (Figure 4). As shown in Section 2, contrary to the maximum of the FWFp (Figure 4a,d), the sums of the FWFp (Figure 4b,e) give the same variations of grey levels as the 986-nm reflectance image (Figure 4c,f). The hyperspectral image, however, displays shadows on the northern aspect because of the $48^{\circ}$ sun elevation from the azimuth $200^{\circ}$, which are not visible on LiDAR max and FWFp sum images. Because of the FWFp spreading through the top of the trees $(T)$ and also the marram grass $(M)$, their maximum appears as darker pixels (Figure 4a,d) than in the FWFp sum (Figure 4b,e) and hyperspectral image (Figure 4c,f). The small waves at the surface of the water produce a lot of bright glint pixels mixed with black pixels in both LiDAR images (Figure $4 \mathrm{~d}$,e), while corresponding hyperspectral pixels are completely black (Figure 4f) because of the difference between their corresponding incident light angles.

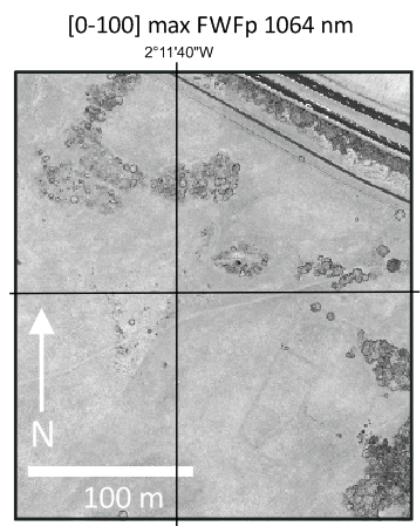

a



d



b



e

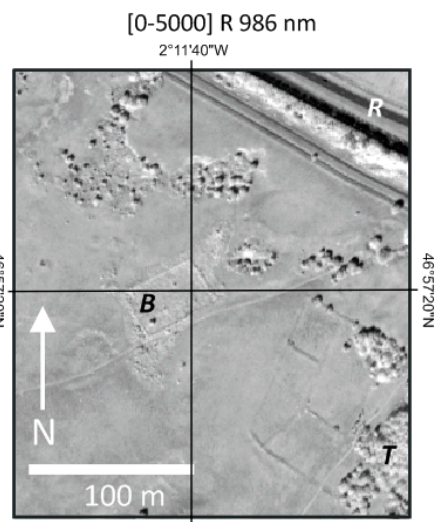

C



Figure 4. Area of interest (AOIs) 1 and 2 located in Figure 1c, showing respectively in (a,d) the maximum intensity of the FWFp, $(\mathbf{b}, \mathbf{e})$ the sum of the FWFp, and $(\mathbf{c}, \mathbf{f})$ the hyperspectral reflectance at $986 \mathrm{~nm}$. Creation of grey scale displays are indicated in brackets.

All low-vegetation and flat surface ROI samples present only one altitude of FWFp (Figure 5a) and discrete echo (Figure 5b), with two echoes when taken from slopes like the dry sand and land ROI examples. Only tree ROI includes multiple FWFp and discrete echoes (Figure 5a,b). This property is classically used for the standard classification of trees with discrete echoes. Low-vegetation types, such as marram grass, display only one single FWFp and discrete echo, requiring the use of FWFp analysis for the extraction of target-type characteristics. A full comparison between discrete echoes and FWFp of marram grass and trees at a one-pixel scale is presented in Figure 5(a2).

The dispersion of the laser beam through the branches and foliage diminishes the maximum FWFp intensity (Figure 4a), which is spread along a large vertical range (Figure 5a) corresponding to the tree outline [31]. FWFp peak intensity is reduced on dark targets, such as road asphalt (Figure 5a) and water, due to low reflectance properties (Figures $4 \mathrm{~b}$ and $5 \mathrm{c}$ ). However, in contrast to the dry 
sand reference, all other FWFp sums at $1064 \mathrm{~nm}$ appear stronger than their corresponding reflectance (Figure 5c), suggesting the contribution of specular reflections. This is mainly due to superficial glint effects, as discussed in Section 2.2.1. This is particularly the case for the bright water FWFp (Figure $4 \mathrm{~d}, \mathrm{e}$ ), where their reflectance is null because of the complete water absorption at $1064 \mathrm{~nm}$ with hyperspectral black pixels (Figure 4f). This effect is seen on leaves and is also present on hyperspectral images (see Figure 9 [32]). The comparison between sand (Figure 3c) and other ROIs (Figure 5c) tell us that LiDAR specular reflection is common and confirms that calibration on diffusive reflectance can be hazardous and would require LiDAR ground control points as shown by [12,25]. As outlined in Section 2.2, we worked around this problem by using FWFp normalizations, removing both altitude and reflectance effects.

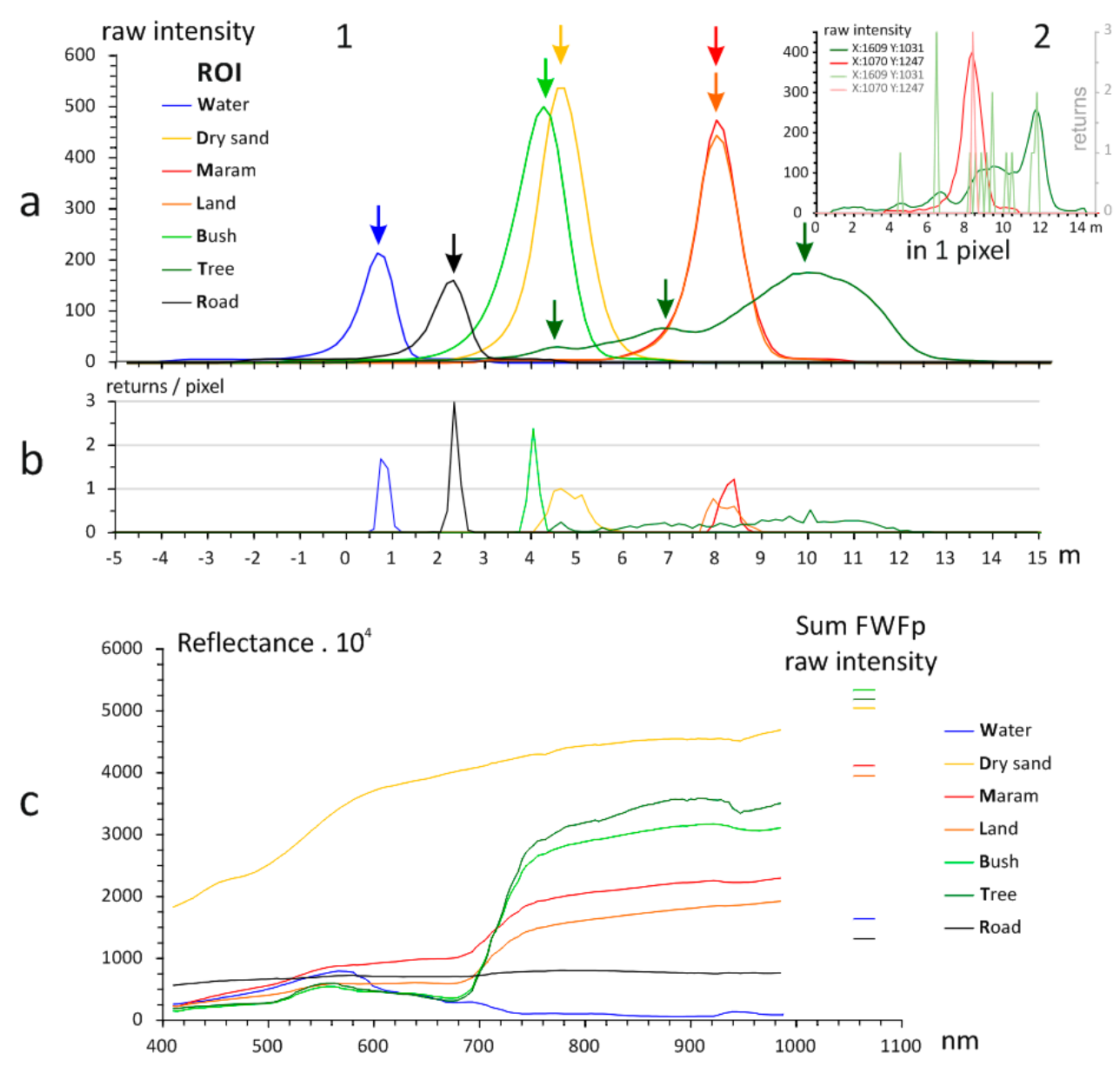

Figure 5. Comparison between echoes, FWFp and hyperspectral spectra. (a) 1: FWFp of seven regions of interest (ROI) located in Figure 1d,e; 2: FWFp and echoes of 2 pixels of sand and tree; (b) distribution of echoes in each ROI; and (c) hyperspectral reflectance of the same ROI and sum of FWFp intensity at $1064 \mathrm{~nm}$.

NCCFWFp aligned on their maximum values_first returns (Figure 6a) —are all concentrated at $0 \mathrm{~m}$ for non-diffusive materials with more or less negative and/or positive enlargements for diffusing materials. The tree sample displays the strongest FWFp downward damping from the top of its canopy, giving the first return. Water and road samples also display FWFp downward damping. But, these are due to superficial roughness, such as capillary waves and asphalt gravel, generating multiple LiDAR glints all along the long damping of the emitted laser beam itself (Figure 6a). A FWFp threshold at 10, as shown in Figure 3g, would almost erase this effect. But then, roads would display only upward FWFp damping as in some low vegetation. This effect was kept to better separate the asphalt from all 
other materials and vegetation types. This is well-evidenced by the NCCFWFp deviation of the dry sand of Figure $6 \mathrm{~b}$. Contrary to other low vegetation on the main land, the marram grass presents an upward FWFp damping, characterizing the polarity of its canopy. The derivative of the NCCFWFp (Figure 6c) displays a more comprehensible color composition (Figure 7), illustrating the enlargement of the FWFp in an upper direction with a longer upward damping function, which does not appear on other low-vegetation types. This effect of upward diffusion in marram grass is best quantified by the calculation of the index $\mathrm{LDI}_{\mathrm{up}}$, which is the area formed between the marram grass NCCFWFp and dry sand reference NCCFWFp (Figure 6b). The deviation from the FWF emission shape (Figure 6d) also shows upward diffusion of the marram grass but with multiple changes of sign not suitable for the definition of a simple index. So, the dry sand reference was again used, displaying a more contrasted curve shape between downward and upward diffusions.


Figure 6. Analysis of normalized cumulative centered FWFp ROI deviations from the dry sand reference: (a) NCCFWFp of six ROIs and the dry sand reference ROI; (b) NCCFWFp deviations of all ROIs (without trees) from the dry sand reference, (c) derivative of the NCCFWFp facilitating its interpretation; and (d) NCCFWFp deviations of all ROIs (without trees) from the emitted pulse.

The color compositions presented in Figure 7 summarize the proposed FWFp analysis. The digital elevation model built on echoes is presented in Figure $7 \mathrm{a}$,e with a false color scale. Figure $7 \mathrm{~b}, \mathrm{f}$ reiterate that FWFp vary with the altitude and that a direct output of their intensity in a color composite image only maps the height of the upper surfaces. The transformation of all FWFp in NCCFWFp, Figure 7c,g, shows the light diffusion characteristics at the surface of materials or in the volume of different vegetation types. Figure $7 \mathrm{~d}, \mathrm{~h}$ use the red, green, and blue channel selection of Figure $6 \mathrm{c}$ to highlight the marram grass in green $(M)$ because of its FWF upward enlargement. All other low-vegetation pixels appear dark (Figure $7 \mathrm{~d}, \mathrm{~h}$ ). Trees and bushes appear in a large palette range from green to blue and magenta because of strong multiple targets generating downward diffusions, whereas water and the road appear magenta because of abundant specular effects along the long damping function of the emitted LiDAR. 
The detection of $0.2-0.5 \mathrm{~m}$-thick tufted, diffuse grasses with a $0.15-\mathrm{m}$ resolution is, however, quite challenging at 1-4 channel heights of FWFp. The random noise produced by such low counts could be partially removed by a classical low-pass filter [33], not used here, to display raw results.

The color composition of red $\mathrm{LDI}_{\mathrm{up}}$, green $\mathrm{LDI}_{\text {mean, }}$ and blue $\mathrm{LDI}_{\text {down }}$ maps of the marram grass area are in orange, low materials, and other vegetation types are in brown (Figure 7d,h). High vegetation types are yellow to cyan because of upward and downward diffusions. Water, asphalt, and wet sand at the bottom of the beach display a cyan hue due to specular glints favored by the long downward damping of the emitted laser beam. The LDI summation smooths the boundaries from wet sand to dry sand, from dry sand to couch grass, and from couch grass to marram grass. Note also the high sensitivity of the method with the detection of a dark footpath $(X)$ in Figure 7h (see also Figure 4).

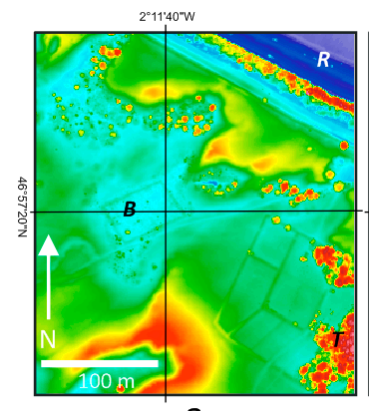

a

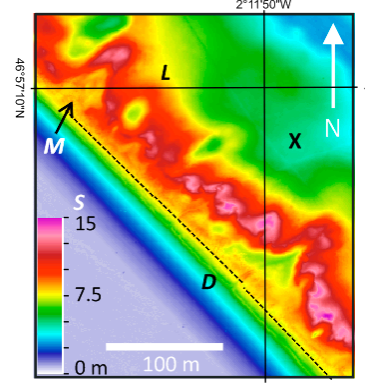

e

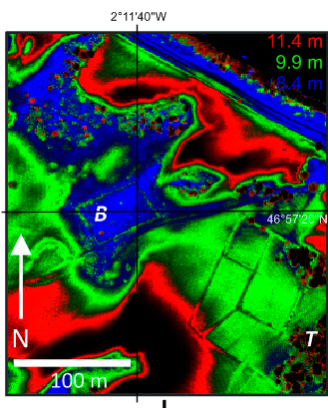

b

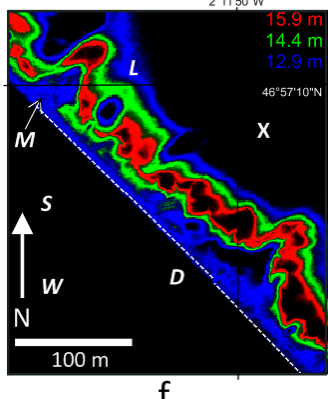

f

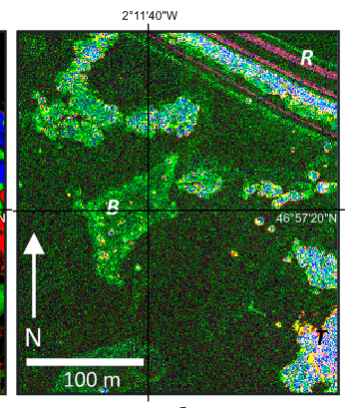

C



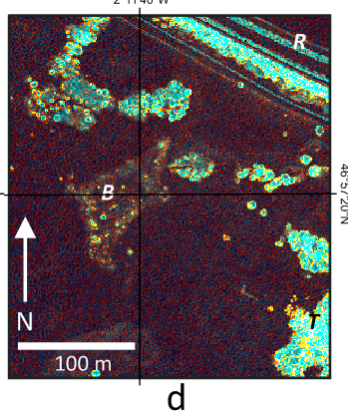

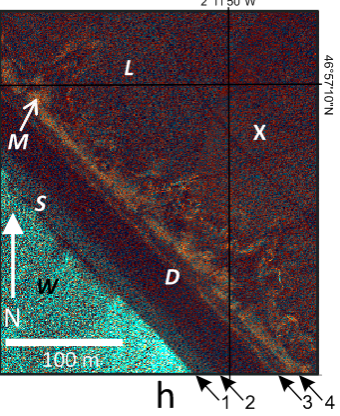

Figure 7. Summary of the FWF analysis: (a,e) DSM built on echoes of both AOIs located in Figure 1c with ROI and marram grass shoreline locations; $(\mathbf{b}, \mathbf{f})$ row FWF color composition using $R, G$, and $B$ intensities taken on three different altitudes in each AOI; (c,g) dNCCFWF color composition using R: $1.15 \mathrm{~m}, \mathrm{G}: 0.40 \mathrm{~m}$, and B: $-2.15 \mathrm{~m}$ selection of Figure $6 \mathrm{c}$, showing sand and low-vegetation types in dark green, marram grass in light green, trees in blue, and water and asphalt in magenta; $(\mathbf{d}, \mathbf{h})$ color composition of R: $\mathrm{LDI}_{\mathrm{up}}, \mathrm{G}$ : $\mathrm{LDI}_{\text {mean }}$ and B: $\mathrm{LDI}_{\mathrm{down}}$. Arrows are boundaries 1: from water to wet sand; 2: from wet sand to dry sand, 3: from dry sand to couch grass; and4: from couch grass to marram grass.

\section{Discussion}

The methodology presented in this paper has many applications. First, it allows a detailed mapping of the low vegetation by relying on its diffusion properties, which are different from the diffusion properties of other foredune and beach surfaces. This full-waveform ray tracing pixel approach is therefore complementary to a spectral or hyperspectral approach. Moreover, the detection of this low-growing vegetation cover allows for the possibility of subtracting it to better understand the real topography of the dune. This would become necessary if a volumetric assessment is carried out and compared from time to time. The aboveground, low-vegetation cover, out of reach of the usual LiDAR classification, is likely to distort volume calculation and can distort the estimation of the sedimentary dynamics. Finally, in the present application, the detection of the first boundary of marram grass at the top of the beach is a key issue in the vulnerability to shoreline erosion along 
the French Atlantic coastline. The Tresson mobile dune is characterized by two successive strips of couch grass and marram grass, respectively, corresponding to incipient foredunes and established foredunes. In 2017 (Figure 1b), the contrast in the physiological state between couch grass and marram grass could be used to draw a boundary, but this was not the case in 2015 (Figure 1e) when both grass types merged. By looking at the vegetation structure and surface roughness, the FWFp provides new information. The boundary between couch grass and marram grass is a straight line (broken line in Figure 1c,e and Figure 7e,f), almost perfectly aligned at a 7.5-m altitude of the DSM, as shown in Figure $4 \mathrm{~b}$. Two other boundaries are also visible, from pioneer couch grass to dry sand at the top of the beach and from dry sand to wet sand at its bottom (see corresponding arrows in Figure $7 \mathrm{~g}, \mathrm{~h}$ ).

\section{Conclusions}

The transformation of laser pulse FWF into pixels of mean FWF by ray tracing (FWFp) maintaining the view angle, the area, and the integration time of the associated hyperspectral pixels, is an effective tool for the characterization of vulnerable shorelines. The use of normalized cumulative centered FWFp enhanced the contrast between low-vegetation types. The normalization step avoiding the use of Gaussian calibration not taking into account low intensities, is crucial for the preservation of the key information carried by the damping function. A full exportation with a scale factor of the emitted FWF would help to better understand the FWF form returns, and we hope that it will soon be available. The long-distance LiDAR measurement with a resolution of $0.15 \mathrm{~m}$ had a noticeable FWFp noise level on 1-4 channel heights of ray tracing pixel, which is inevitable. However, the summation by LiDAR diffusion indices reduces that noise and helps with the shoreline mapping. An increase of the record frequency could improve this limitation, given by nanosecond digitization. Wet sand to dry sand, dry sand to couch grass, and couch grass to marram grass are potential indicators routinely used in shoreline studies. The key issue is the detection of upward and downward FWFp diffusion with respect to the first return or echo marking of the main altitude of a surface. Marram grass, the only vegetation to present strong (multiple micro-targets) upward diffusion along the sandy shoreline, can be easily monitored on successive FWFp acquisition. During low tide, another boundary between the (water table) wet sand and more or less dry sand can also be monitored along the straight interface between flat compact materials with strong glint effects, forming apparent downward diffusion, and soft materials (standard sand), presenting only upward diffusion. Future works will address the full combination of the LiDAR FWFp images with optical hyperspectral images acquired synchronously from the same aircraft and explore the benefits for more accurate classification of low-lying vegetation and water contents.

Supplementary Materials: The following are available online at http:/ /www.mdpi.com/2072-4292/10/5/669/s1, S1: data and calculations of Figure 3, Figure 5, and Figure 6.

Author Contributions: A.B., P.L., and S.M. developed the voxelization approach of the FWF processing and M.G. provided P.L. with the ray tracing approach highlighted in this work; geomorphology and vegetation were controlled by M.R. and F.D.; M.G. and P.L. operated the airborne hyperspectral camera; D.L. was involved with P.L., M.G., and E.L.M. in the FWF LiDAR settings and analysis; A.B., F.D., M.R., M.G., and P.L. did the ground truthing; and P.L., A.B., M.R., and S.M. wrote the paper.

Acknowledgments: We would like to thank William Gentile, Cyril Michon, and Emmanuel Gouraud from GEOFIT Company, Jean-Jérôme Houdaille from PIXAIR Compagny, Paul La Rocque and Anca Dobrinescu from Teledyne Optech Compagny. This research was supported by the Region Pays de la Loire with funding of the RS2E-OSUNA and OR2C programs. The Nantes Rennes LiDAR platform was funded by the Region Pays de la Loire and the Region Bretagne with European Regional Development Fund (ERDF). The LPG hyperspectral camera was funded by the Contrat de Projet Etat Region des Pays de la Loire (CPER R 51_p6 2007-2013) with ERDF funds.

Conflicts of Interest: The authors declare no conflict of interest. 


\section{References}

1. Orlikowska, E.H.; Roberge, J.-M.; Blicharska, M.; Mikusiski, G. Gaps in ecological research on the world's largest internationally coordinated network of protected areas: A review of Natura 2000. Biol. Conserv. 2016, 200, 216-227. [CrossRef]

2. Ruz, M.H.; Meur-Ferec, C. Influence of high water levels on aeolian sand transport: Upper beach/dune evolution on a macro tidal coast, Wissant Bay, northern France. Geomorphology 2003, 60, 73-87. [CrossRef]

3. Sabatier, F.; Anthony, E.J.; Hquette, A.; Suanez, S.; Musereau, J.; Ruz, M.-H.; Regnauld, H. Morphodynamics of beach/dune systems: Examples from the coast of France. Géomorphologie 2009, 15, 3-22. [CrossRef]

4. Juigner, M.; Robin, M.; Debaine, F.; Hélen, F. A generic index to assess the building exposure to shoreline retreat using box segmentation: Case study of the Pays de la Loire sandy coast (west of France). Ocean Coast. Manag. 2017, 148, 40-52. [CrossRef]

5. Hertling, M.U.; Lubke, A.R. Use of Ammophila arenaria for Dune Stabilization in South Africa and Its Current Distribution Perceptions and Problems. Environ. Manag. 1999, 24, 467-482. [CrossRef]

6. Hesp, P.A.; Walker, I.J. Coastal dunes. In Treatise on Geomorphology; Shroder, J., Lancaster, N., Sherman, D.J., Baas, A.C.W., Eds.; Academic Press: Cambridge, MA, USA, 2013; Volume 11, pp. 328-355.

7. Spaete, L.P.; Glenn, N.F.; Derryberry, D.R.; Sankey, T.T.; Mitchell, J.J.; Hardegree, S.P. Vegetation and slope effects on accuracy of a LiDAR-derived DEM in the sagebrush steppe. Remote Sens. Lett. 2011, 2, 317-326. [CrossRef]

8. Maun, A. The Biology of Coastal Sand Dunes; Oxford University Press: Oxford, UK, 2009; 265p.

9. Baltsavias, E.P. Airborne laser scanning: Existing systems and firms and other resources. ISPRS J. Photogramm. Remote Sens. 1999, 54, 164-198. [CrossRef]

10. Mallet, C.; Bretar, F. Full-waveform topographic lidar: State-of-art. ISPRS J. Photogramm. Remote Sens. 2009, 64, 1-16. [CrossRef]

11. Doyle, T.B.; Woodroffe, C.D. The application of LIDAR to investigate foredune morphology and vegetation. Geomorphology 2018, 303, 106-112. [CrossRef]

12. Wagner, W.; Hollaus, M.; Briese, C.; Ducic, V. 3D vegetation mapping using small-footprint full-waveform airborne laser scanners. Int. J. Remote Sens. 2008, 29, 1433-1452. [CrossRef]

13. Richter, R.D. Atmospheric/Topographic Correction for Airborne Imagery. In DLR Report; DLR-IB 565-02/14, 240; DLR: Wessling, Germany, 2014.

14. Persson, A.; Sderman, U.; Tpel, J.; Ahlberg, S. Visualization and analysis of full waveform airborne laser scanner data. In Proceedings of the ISPRS Workshop “Laser Scanning 2005”, Enschede, The Netherlands, 12-14 September 2005; pp. 103-108.

15. Wang, H.; Glennie, C.; Prasad, S. Voxelization of full waveform LiDAR data for fusion with hyperspectral imagery. In Proceedings of the IEEE International Geoscience and Remote Sensing Symposium-IGARSS, Melbourne, Australia, 21-26 July 2013; pp. 3407-3410.

16. Wang, H.; Glennie, C. Fusion of waveform LiDAR data and hyperspectral imagery for land cover classification. ISPRS J. Photogramm. Remote Sens. 2015, 108, 1-11. [CrossRef]

17. Buddenbaum, H.; Seeling, S.; Hill, J. Fusion of full-waveform lidar and imaging spectroscopy remote sensing data for the characterization of forest stands. Int. J. Remote Sens. 2013, 34, 4511-4524. [CrossRef]

18. Hermosilla, T.; Ruiz, L.A.; Kazakova, A.N.; Coops, N.C.; Moskal, L.M. Estimation of forest structure and canopy fuel parameters from small-footprint full-waveform LiDAR data. Int. J. Wildland Fire 2014, 23, 224-233. [CrossRef]

19. Nie, S.; Wang, C.; Zeng, H.; Xi, X.; Li, G. Above-ground biomass estimation using airborne discrete-return and full-waveform LiDAR data in a coniferous forest. Ecol. Indic. 2017, 78, 221-228. [CrossRef]

20. Hapke, B. Bidirectional reflectance spectroscopy: 1. Theory. J. Geophys. Res. 1981, 86, 3039-3054. [CrossRef]

21. Despan, D.; Bedidi, A.; Cervelle, B.; Rudant, J.-P. Bidirectional reflectance of gaussian random surfaces and its scaling properties. Math. Geol. 1998, 7, 873-888. [CrossRef]

22. Wagner, W. Radiometric calibration of small-footprint full-waveform airborne laser scanner measurements: Basic physical concepts. ISPRS J. Photogramm. Remote Sens. 2010, 65, 505-513. [CrossRef]

23. Wagner, W.; Ullrich, A.; Ducic, V.; Melzer, T.; Studnicka, N. Gaussian decomposition and calibration of a novel small-footprint full-waveform digitizing airborne laser scanner. ISPRS J. Photogramm. Remote Sens. 2006, 60, 100-112. [CrossRef] 
24. Ullrich, A.; Pfennigbauer, M. Echo Digitization and Waveform Analysis in Airborne and Terrestrial Laser Scanning; Photogrammetric Week 11; Fritsch, D., Ed.; Wichmann/VDE Verlag: Belin/Offenbach, Germany, 2011; pp. 217-228.

25. Höfle, B.; Pfeifer, N. Correction of laser scanning intensity data: Data and model-driven approaches. ISPRS J. Photogramm. Remote Sens. 2007, 62, 1415-1433. [CrossRef]

26. Krooks, A.; Kaasalainen, S.; Hakala, T.; Nevalainen, O. Correction of Intensity Incidence Angle Effect in Terrestrial Laser Scanning. ISPRS Ann. Photogramm. Remote Sens. Spat. Inf. Sci. 2013, 2, 145-150. [CrossRef]

27. Clark, N.R.; Roush, T.D. Reflectance spectroscopy: Quantitative analysis techniques for remote sensing applications. J. Geophys. Res. 1984, 89, 6329-6340. [CrossRef]

28. Jutzi, B.; Stilla, U. Range determination with waveform recording laser systems using a Wiener filter. ISPRS J. Photogramm. Remote Sens. 2006, 61, 95-107. [CrossRef]

29. Parrish, C.E.; Rogers, J.N.; Calder, B.R. Assessment of waveform features for LiDAR Uncertainty Modeling in a coastal salt marsh environment. IEEE Geosci. Remote Sens. Lett. 2013, 11, 569-573. [CrossRef]

30. Hovi, A.; Korhonen, L.; Vauhkonen, J.; Korpela, I. LiDAR waveform features for tree species classification and their sensitivity to tree- and acquisition related parameters. Remote Sens. Environ. 2016, 173, 224-237. [CrossRef]

31. Jutzi, B.; Stilla, U. Waveform processing of laser pulses for reconstruction of surfaces in urban areas. Meas. Tech. 2005, 2, 2.

32. Launeau, P.; Kassouk, Z.; Debaine, F.; Roy, R.; Mestayer, P.G.; Boulet, C.; Rouaud, J.-M.; Giraud, M. Airborne hyperspectral mapping of trees in an urban area. Int. J. Remote Sens. 2017, 38, 1277-1311. [CrossRef]

33. Jähne, B. Digital Image Processing, Concepts, Algorithms and Scientific Applications; Springer: Berlin, Germany, $1991 ;$ p. 383.

(C) 2018 by the authors. Licensee MDPI, Basel, Switzerland. This article is an open access article distributed under the terms and conditions of the Creative Commons Attribution (CC BY) license (http:/ / creativecommons.org/licenses/by/4.0/). 